\title{
Neuromechanical coupling during mechanical ventilation: reverse-triggering vs others forms of asynchrony
}

\author{
JA Benitez Lozano', F Ruiz Ferron², P Carmona Sanchez ${ }^{3}$, JM Serrano Simon ${ }^{3 *}$ \\ From ESICM LIVES 2015 \\ Berlin, Germany. 3-7 October 2015
}

\begin{abstract}
Introduction
The term "respiratory entrainment" refers to of coupling patterns between the rhythm neuronal and mechanical of ventilator to achieve satisfactory synchrony. Respiratory effort stimulated by the mechanical inspiratory flow or reverse trigger (RT), has been recently demonstrated [1]. This asynchrony is difficult to showed without additional signals as esophageal pressure or electrodiaphragmatic signal.
\end{abstract}

\section{Objectives}

To use a method to differenciate this asynchrony by the standard signals of the ventilator, using an occlusion maneuver and to show the characteristics of this RT.

\section{Methods}

Over 4-month from December-2014 we studied a group of consecutive ventilated patients because they showed too high respiratory drive, beside they were sedated and assist-volume control mechanical ventilation was changed trying improve ventilator interaction. Signals of flow, airway and pleural or esophageal pressure were registered during $3 \mathrm{~min}$ for ulterior analysis. Passive respiratory mechanics were measured by multiple linear regression. Entrainment pattern we evaluated by measure of mechanical and neural respiratory times (Ttotm, Ttotn), and repetitive phase of ventilatoy cycles. On apparent reverse triggering we carried out an occlusion maneuver. Gasometric data was recording. We classified entrainment ratio. Data were analyzed by descriptive statistical and are expressed as mean $\pm \mathrm{SD}$, medians [IRQ] and coefficient of variation (CV). Comparison of ventilator and neural cycle, and phase angle of apparent reverse triggering vs total asynchronic identified by occlusion maneuvers were performed with test Mann-Whitney.

\section{Results}

5 of 12 patients were identified for study, 4 patients postoperative lung transplant and 1 with ARDS. Age $50 \mathrm{yr}(41,25-56,25)$. The patients with RT (N3) showed minimal variability in neuromechanical coupling pattern and had no respiratory activity after occlusion maneuver. The periods of entrainment varying from 40 to $90 \%$ of recording time. The 1:1 pattern was dominant. For all data: Respiratory system elastance and resistances $35 \pm$ $7,9 \mathrm{cmH} 2 \mathrm{O} / \mathrm{L}$ and 16,86 $\pm 6,6 \mathrm{cmH} 2 \mathrm{O} / \mathrm{L} / \mathrm{s}$. Mechanical and neural respiratory time $3 \mathrm{~s}(2,88-3,02)$ and $3,1 \mathrm{~s}(2,98-$ $3,44)$; phase angle $61,94^{\circ}(49,79-99,14)$. Tidal volume $0,52 \mathrm{~L} \pm 0,02$. RR $21,20 \pm 1,64 / \mathrm{min}$. PaCO2 49,8 \pm $8,04 \mathrm{mmHg}$. CV for reverse triggering vs asynchrony: Ttotm $14 \%$ vs $14,86 \%$; Ttotn $7 \%$ vs $16,45 \%$; phase $17,25 \%$ vs $26,48 \%(\mathrm{p}<0,001)$.

\section{Conclusions}

This method is useful to demonstrate RT vs overall asynchrony. RT is characterized by: 1) The less variability between mechanical and neural respiratory cycle involves a fixed neuromechanical coupling. 2) Absence of spontaneous breathing activity, manifested after occlusion maneuver. 


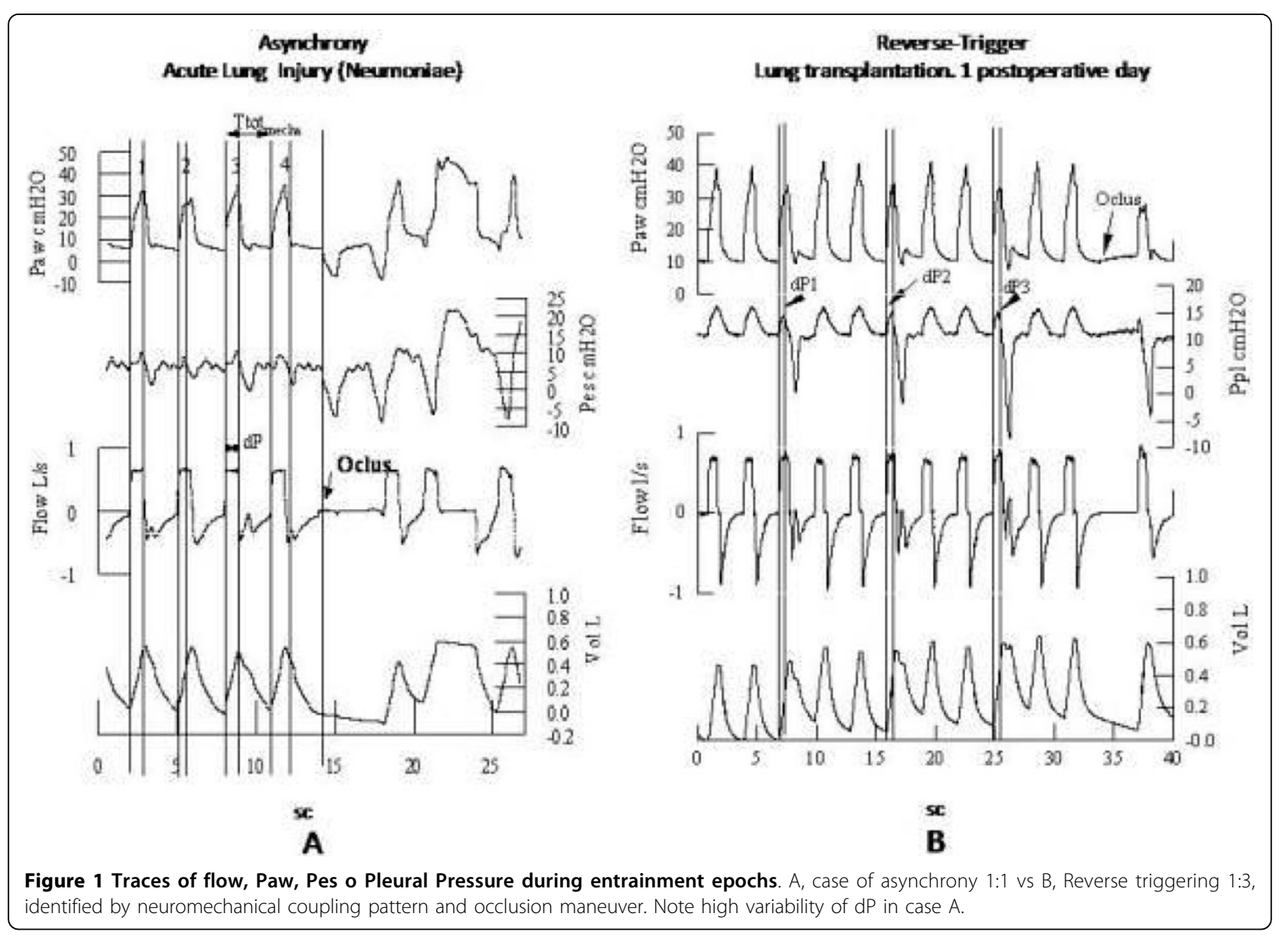

Authors' details

${ }^{1}$ Hospital Quiron, Malaga, Spain. ${ }^{2}$ Complejo Hospitalario de Jaen, Intensive Care Unit, Jaen, Spain. ${ }^{3}$ Hospital Universitario Reina Sofia, Intensive Care Unit, Cordoba, Spain.

Published: 1 October 2015

\section{Reference}

1. Akoumianaki E: Chest 2013, 143(4):927.

doi:10.1186/2197-425X-3-S1-A997

Cite this article as: Benitez Lozano et al: Neuromechanical coupling during mechanical ventilation: reverse-triggering vs others forms of asynchrony. Intensive Care Medicine Experimental 2015 3(Suppl 1):A997.

Submit your manuscript to a SpringerOpen ${ }^{\circ}$ journal and benefit from:

- Convenient online submission

- Rigorous peer review

- Immediate publication on acceptance

- Open access: articles freely available online

- High visibility within the field

- Retaining the copyright to your article

Submit your next manuscript at $>$ springeropen.com 